\title{
The Recovery from Alcohol Consumption: Analysis of the Construct of Relapse
}

\author{
La recuperación del consumo de alcohol: análisis del constructo de recaída
}

Hugo E. Reyes-Huerta ${ }^{\text {* }}$, Ángeles Vacio², Francisco Pedroza², Martha Salazar², Kalina Martínez²

\begin{abstract}
Objective: A systematic review was conducted to identify definitions that facilitated the study of relapse as both behavioral pattern and process. Methods: The review was conducted following the PRISMA-P guidelines. Articles that met the following inclusion criteria were considered: (a) published in peerreviewed journals, (b) provided an explicit operational definition of relapse, (c) assessed relapse during or after a specific psychological or self-care group intervention, (d) focused on alcohol consumption, and (e) were published between 2000 and September 2016. Results: "Any drinking" was the most frequent outcome used to identify relapse, although other discrete outcomes were also considered. Nevertheless, none of the definitions operationalize the notion of the return to a problematic drinking pattern and/or the process of relapse. Conclusion: Problems related to any drinking definition are discussed and we propose the use of a composed index to study relapse.

\section{Resumen}

Objetivo: Se realizó una revisión sistemática para identificar definiciones que permitieran el estudio de la recaída como un patrón y proceso conductual. Método: La revisión fue realizada siguiendo los lineamientos de la guía PRISMA-P. Los artículos que cumplían con los siguientes criterios fueron revisados: (1) publicados en revistas con revisión por pares, (b) definían explícitamente la recaída, (c) se evaluó la recaída después o durante un tratamiento psicológico o participación en un grupo de autoayuda, (d) la intervención se enfocaba en el consumo de alcohol, (d) publicados entre el año 2000 y septiembre de 2016. Resultados: Cualquier consumo fue el resultado más frecuentemente usado para definir la recaída, aunque otros resultados discretos también se consideraron. No obstante, ninguna de las definiciones operacionales reflejó la noción del regreso a un patrón de consumo problemático y/o el proceso a la recaída. Conclusiones: Problemas relacionados a la definición de cualquier consumo son discutidos y se propone un índice compuesto para estudiar la recaída.
\end{abstract}

\section{Keywords:}

alcohol consumption, relapse, treatment outcomes, pattern, process

Palabras clave:

consumo de alcohol, recaída, resultados del tratamiento, patrón, proceso

1. CONACYT - Universidad Autónoma de Aguascalientes, Aguascalientes, Ags., México.

2. Universidad Autónoma de Aguascalientes, Aguascalientes, Ags., México.

*Corresponding author. hugo.reyes@edu.uaa.mx

Manuscript received 2017-11-01 revised 04-12-2017; accepted 13-12-2017.

\section{Introduction}

Despite the resources used to treat alcoholism, efficient programs to reduce relapse after treatment remain a critical need in the health care systems (Mundt, Moore \& Bean, 2006). Even though health professionals implement some relapse prevention strategies, the lack of maintenance of clinical progress over time is a common result (McKay, Franklin, Patapis, \& Lynch, 2006; Scott, Dennis, \& Foss, 2005; Zweben \& Cisler, 2003). As a consequence, the relapse rate is a good indicator to guide clinical decisions about intervention courses, to compare the effectiveness of treatments, and to determine the accumulation and transference of knowledge for treatments (Sobell, Sobell, Connors, \& Agrawal, 2003). 
Given the relevance of relapse to understanding recovery from alcoholism, researchers and clinicians have been interested in the analysis of conditions that improve the description and explanation of this treatment outcome. In this sense, the analysis of issues such as the appropriate methodology to study relapse (e.g. prospective, retrospective or ecological momentary assessment), the correct analytical methods applied to relapse data or how technologies can allow a near-time characterization of relapse, are current topics in the investigation agenda (Chung \& Maisto, 2006; Maisto \& Connors, 2006; McKay et al., 2006). However, to improve understanding of relapse, researchers need to solve a crucial problem: the lack of consensus in what is a relapse.

As Maisto and Connors (2006) noted, "arriving at an operational definition of relapse for a given behavior that is acceptable to researchers and clinicians alike is daunting" (p. 230). Relapse has been defined by researchers in several ways without a clear correspondence between the conceptual and operational levels (Marlatt \& Donovan, 2005; Marlatt \& Witkiewitz, 2002; Zweben \& Cisler, 2003; Witkiewitz \& Marlatt, 2011). Consequently, there are a large number of definitions of the relapse construct, limiting clinical judgments to results in a particular study in the best of cases, but making cross-study comparisons difficult. Furthermore, the asymmetry between the conceptual and operational definition of relapse usually results in uninformative measures of the concept (Moyer, Finney \& Swearingen, 2002; Sobell et al., 2003; Takeda, Roper, Duff \& Booth, 2013).

For example, the asymmetry between the conceptual and operational definition of relapse has resulted in contradictory judgments about relapse rate. Tuithof, ten Have, van den Brink, Vollebergh and Graaf (2014) justified the need for relapse prevention measures because of the high personal and social costs associated with alcohol use disorder, "even though relapse rates are low" (p.85). The authors argue that just a minority of patients experience a relapse within the first three years in which they go into remission. On the other hand, Witteman et al. (2015) argue that identifying risk factors to a relapse is a primary task since dependence on alcohol is characterized by high rates of relapse into a problematic drinking behavior after a successful treatment. Both affirmations result from different variables, but clearly reflect the importance of precisely operationalizing the concept. An evaluation of the relationship between conceptual and operational definitions can help to favor some definitions of relapse over others.

The notion of problematic drinking patterns and the conceptualization of relapse as a process are two common elements in the conceptual definition of relapse-but not at the operational level (Marlatt \&
Witkiewitz, 2002; Zweben \& Cisler, 2003). In relation to the first matter, Miller (1996) noted that drinking patterns are composed of different dimensions (e.g. a reset period, a threshold of consumption, the frequency of alcohol drinking, duration of the drinking episode, and negative consequences). Therefore, the challenge is to assess if some measure of relapse is sensitive and reflects changes in the whole drinking pattern and not just one dimension.

The "drinking pattern" is usually reduced to the amount of alcohol (any drinking or drinking over a threshold) (Maisto, Witkiewitz, Moskal, \& Wilson, 2016; Rahill, Pinto Lopez, Vanderbiest, \& Rice, 2009) and consequently, some aspects remain unclear. For example: (1) how other dimensions are related to the amount of alcohol (e.g. if negative consequences are additive or equivalent to the amount of alcohol); (2) if the reduction of negative consequences is a good outcome criterion with clinical significance; (3) if the determined heavy drinking (based on a drinking threshold) is a standard measure generalized to different individuals or populations; (4) how the consumption pattern(s) change during and after treatment (e.g. if the amount of alcohol consumed per drinking episode remains constant across time, but drinking episodes occurs with less frequency or vice versa). As a result, the ways to leave the wagon anticipated by Miller (1996) remain unclear.

The second challenge is to assess if measuring discrete outcomes is sufficient to conduct a comprehensive study of the difficulties in sustaining clinical change over time. Relapse is conceptualized as a process, but measured as a discrete event (Potgieter, Deckers, \& Geerlings, 1999; Marlatt \& Witkiewitz, 2002). As Maisto et al. (2016), discussed, increasing the heuristic value of the construct of relapse depends on understanding relapse as a recovery process. Attending the process of relapse will imply at least (1) considering the common distinction between lapse and relapse, where the first supposes a consumption that is expected in the recovery process, (2) according to Takeda et al. (2013) "look[ing] at the whole process of relapse" (p. 418), which requires the analysis of variables related to relapse before, during, at the end and after drinking episodes, (3) analyzing multiple drinking episodes over time and not just an isolated one, using broader descriptive categories (Chung, Maisto, Cornelius, \& Martin, 2004; Greenwood, Woods, Guydish, \& Bein, 2001; Walton, Castro, \& Barrington, 1994), such as drinking trajectories (Witkiewitz \& Masyn, 2008); or analyzing the consistency of risk factors or coping strategies across drinking episodes (McKay et al., 2006; Ramo, Prince, Roesch, \& Brown, 2012), (4) designing longitudinal studies, and (5) analyzing individual processes (changes in drinking patterns can represent different levels of progress or risk in particular cases). 
Increasing the heuristic value of the construct of relapse requires a systematic evaluation of a relapse definition that facilitated cross-study comparisons reflecting the drinking pattern. Previously obtained results utilized a large number of definitions in the study of relapse (Maisto et al., 2016; Rahill et al., 2009). Nevertheless, it is not clear if actual measures of relapse are sensitive to both drinking patterns and the process of returning to problematic drinking.

The present review looks at the indicators that can be used to understand relapse as a pattern of consumption and as a process. First, it identifies the frequency with which a dimension or a set of dimensions was used to define relapse. Second, it looks possible relationships between the different dimensions used to measure relapse. Third, it evaluates if relapse was considered to be a discrete outcome or a process (e.g. measured by drinking patterns before, during and after treatment; lapse/relapse distinction; analyses of trajectories or multiple episodes; longitudinal designs; and descriptions of individual processes). Fourth, it identifies theoretical or empirical criteria explicitly used to favor a particular definition of relapse. Fifth, it compares relapse rates as a function of the definition of relapse that we found. Finally, it integrates some of the conditions that can improve our understanding of relapse as a pattern and process.

\section{Method}

A systematic review of the operational definition of alcohol consumption relapse was conducted following the PRISMA-P guidelines (Moher et al., 2015).

\section{Inclusion/exclusion criteria}

Considering the purpose of the review, articles were reviewed if they: (a) were published in peer-reviewed journals; (b) described an explicit operational definition of relapse--articles that did not were excluded even if the definition could be inferred; (c) assessed relapse during or after a specific psychological or self-care group intervention (these interventions could either be complemented by pharmacological treatment or not, we considered them relevant as a reference point since criteria for a reset period (remission) do not exist; (d) studied interventions focused on alcohol consumption; and (e) were published between 2000 and September 2016. The analyses were not restricted by the age or gender of the participants, nor by region or language of publication.

\section{Literature research}

The research was conducted via an electronic database (PsycINFO, PsycArticle, and Web of Science) using a combination of the next terms: ("alcohol") AND ("relapse" OR "lapse") AND ("prevention" OR "treatment" OR "intervention"). Documents were identified from the correspondence of the terms used with the title, the abstract or the key words. The resulting documents were screened based on title and abstract, and the selected articles were assessed for eligibility.

In a second review, called retrospective research (Card, 2012), we looked for articles in the reference section that could be included in the review. Finally, a prospective research was also conducted using PubMed and Google Scholar to identify documents that cited the articles already retrieved.

\section{Elements of interest}

With articles that met inclusion criteria we identify the following elements in the operational definition or definitions of relapse in order to assess if the operationalization of the term reflect drinking patterns, considering: (1) the dimensions considered to operationalize relapse (e.i. reset period, any drinking, threshold, frequency, and negative consequences) and the combination of these; (2) the identification of relapse as a discrete or continuous measure (e.g. categories such as heavy drinking or as an index); (3) the measure of the drinking pattern before treatment (used to obtain a reference point for the return to problematic drinking); and (4) justifications about the dimensions and the values used. Finally, to assess if the operationalization of the term reflected the notion of process, we considered: (a) the lapse/ relapse distinction; (b) if the consumption pattern was evaluated before, during or after treatment; (c) the moment and number of evaluations of relapse; (d) the analyses of trajectories or multiple episodes; (e) the duration of the study and use of longitudinal designs; and $(f)$ the description of individual processes.

\section{Results}

A total of 1, 689 articles were retrieved with database research and 24 with retrospective and prospective research. After that, duplicate articles were removed, 1, 340 titles were screened and their abstracts examined; 1, 289 articles were excluded and 51 full-text articles were assessed for eligibility. Finally, 18 articles met all inclusion criteria (see Figure 1). 
Figure 1.

PRISMA flow diagram of search strategy

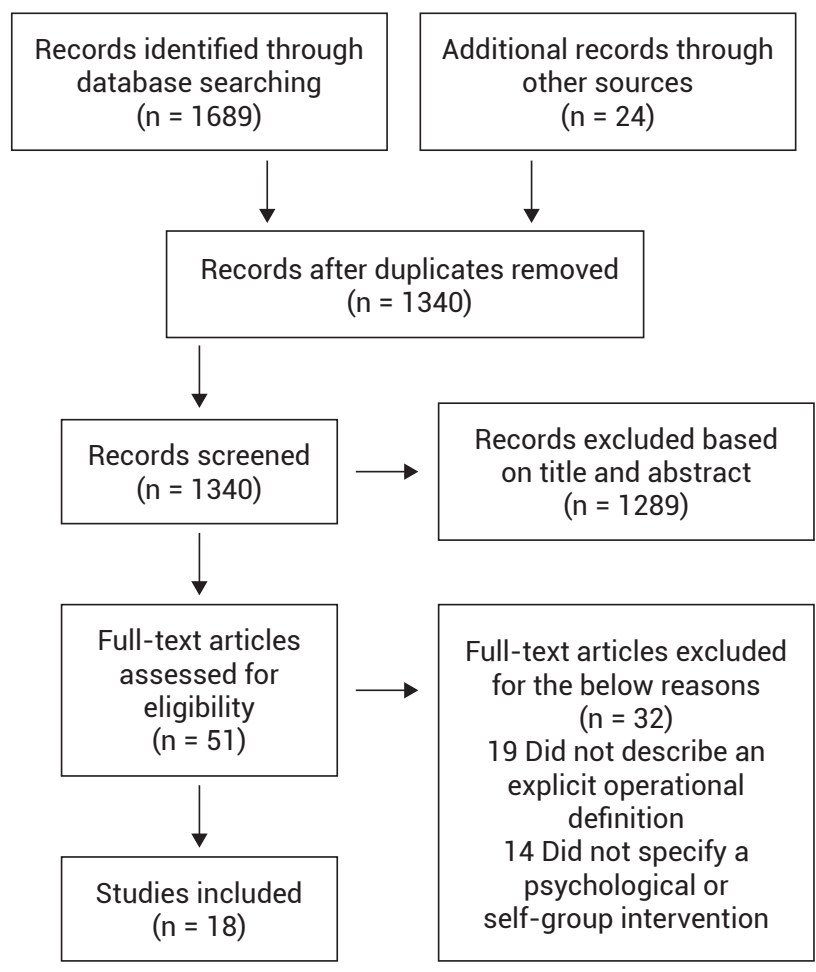

In relation to the conceptualization of the drinking pattern, Figure 2 shows the frequency of dimensions used. The most frequent definition was based on any drinking: seven times as the unique indicator, five times preceded by a reset period, and two times associated with frequency (e.g. any drinking after three consecutive days of abstinence). The second most frequent definition was based on a threshold of consumption: the amount of alcohol was used on three occasions as a unique dimension, two times it was associated with frequency, one time it was preceded by a reset period, one time it was associated with negative consequences, and four times it was associated with another two dimensions. The third most frequent definition was based on negative consequences. In most of the cases it appeared in association with another dimension, while only one article used negative consequences as the unique indicator. The fourth most frequent definition was based on the frequency of drinking: in two cases it was associated with a threshold of consumption and the other two times with any drinking. Finally, a reset period was used preceding any drinking and the threshold of consumption, three and two times respectively. In all the cases, dimensions were measured as discrete categories.

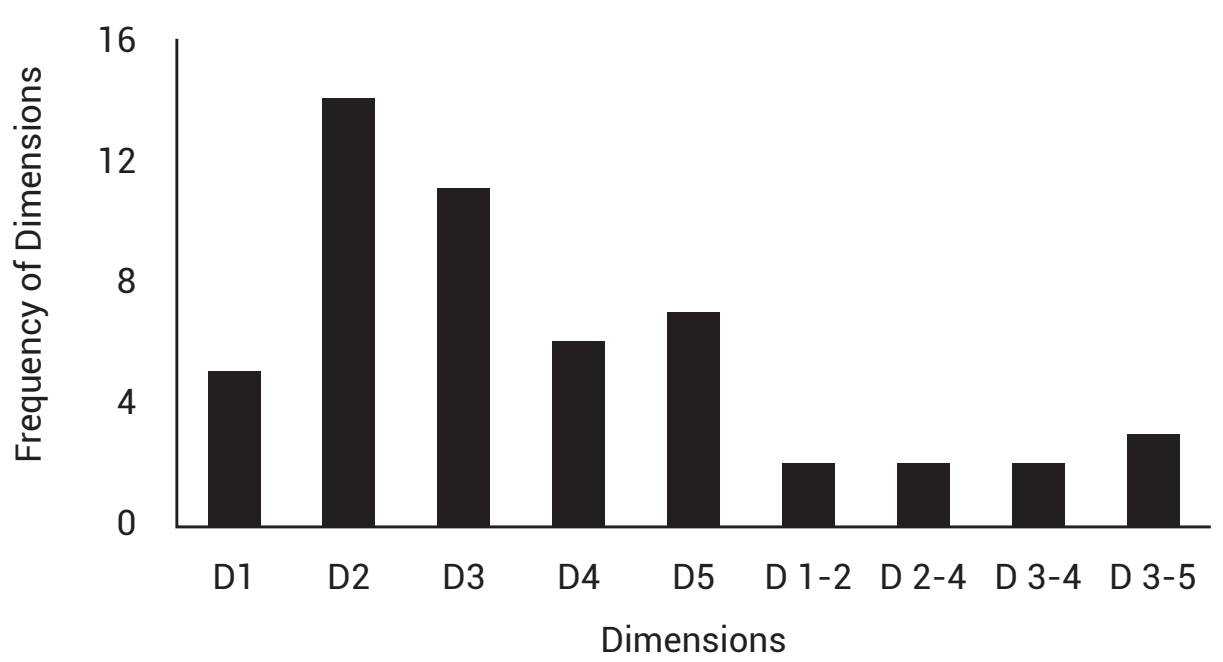

Figure 2. Dimensions and combination of dimensions used to operationalize relapse: Days of abstinence (D1), any drinking (D2), a threshold (D3), frequency (D4), and negative consequences (D5).

Table 1 summarizes the operational definitions described in the articles under review. In relation to the values of the dimensions used to define relapse, results showed that values differed across studies. For example, in the case of consumption threshold, the amount of alcohol ranged from 4 up to 31 standard drinks, or from $30 \mathrm{~g}$ up to $60 \mathrm{~g}$ of alcohol. In the case of drinking frequency, relapse was identified considering two drinking episodes in a week, or more than five episodes in the same period. Only two studies had a reset period as an element of the relapse definition, in both cases, four days in remission was needed to identify a relapse. Finally, negative consequences were associated with hospitalizations and legal or personal problems. 
Table 1

Operational definitions of relapse used: dimensions and values.

\begin{tabular}{|c|c|c|c|c|c|c|c|}
\hline $\begin{array}{l}\text { Study } \\
\text { No. }\end{array}$ & $\begin{array}{l}\text { First } \\
\text { author Year } \\
\text { published }\end{array}$ & $\begin{array}{l}\text { Independent } \\
\text { Variable }\end{array}$ & Operational definition & $\begin{array}{l}\text { Lapse/ } \\
\text { Relapse } \\
\text { (Distinction) }\end{array}$ & Moment & $\begin{array}{l}\text { Study } \\
\text { Duration } \\
\text { (months) }\end{array}$ & $\begin{array}{l}\text { Relapse rate } \\
\text { measures }\end{array}$ \\
\hline 1 & $\begin{array}{l}\text { Zywiak et al., } \\
2006\end{array}$ & $\begin{array}{l}\text { Gender and } \\
\text { relapse type }\end{array}$ & $\begin{array}{l}\text { 1) } 4 \text { consecutive days of abstinences - } \\
\text { Any drinking }\end{array}$ & No & $\mathrm{PT} *$ & 12 & $62 \%$ \\
\hline 2 & $\begin{array}{l}\text { Wetzel et al., } \\
2004\end{array}$ & $\begin{array}{l}\text { Type of } \\
\text { treatment }\end{array}$ & $\begin{array}{l}\text { 1) Any drinking } \\
\text { 2) Threshold ( } 60 \mathrm{~g} \text { ) or } 3 \text { ) Hospitalization }\end{array}$ & $\mathrm{No} * *$ & PT & 12 & $\begin{array}{l}49 \% / 77 \% \\
46 \% / 76 \%\end{array}$ \\
\hline 3 & $\begin{array}{l}\text { Maisto et al., } \\
2003\end{array}$ & $\begin{array}{l}\text { Operational } \\
\text { definition }\end{array}$ & $\begin{array}{l}\text { 1) } 4 \text { consecutive days of abstinences - } \\
\text { Any drinking } \\
\text { 2) } 4 \text { consecutive days of abstinences - } \\
\text { Threshold ( } 4 \text { standard drinks for females } \\
\text { and } 5 \text { standard drinks for males) } \\
\text { 3) } 4 \text { consecutive days of abstinences - } \\
\text { Any drinking - Drinking with problems } \\
\text { 4) } 4 \text { consecutive days of abstinences - } \\
\text { Threshold ( } 4 \text { standard drinks for females } \\
\text { and } 5 \text { standard drinks for males) - } \\
\text { Drinking with problems }\end{array}$ & No & PT & 6 & $\begin{array}{l}74 \% \\
62 \% \\
60 \% \\
50 \%\end{array}$ \\
\hline 4 & $\begin{array}{l}\text { Mertens et } \\
\text { al., } 2012\end{array}$ & $\begin{array}{l}\text { Abstinence } \\
\text { versus non- } \\
\text { problematic } \\
\text { drinking }\end{array}$ & $\begin{array}{l}\text { 1) Threshold ( } 5 \text { standard drinks) - } 4 \\
\text { drinking days per month - Use of other } \\
\text { substance - Interpersonal and/or legal } \\
\text { problems }\end{array}$ & Yes & PT & 132 & $51 \%$ \\
\hline 5 & $\begin{array}{l}\text { Bottlender et } \\
\text { al., } 2004\end{array}$ & Risk factors & $\begin{array}{l}\text { 1) Any drinking (during treatment) } \\
\text { 2) More than three drinking episodes of } \\
\text { more than } 30 \mathrm{~g} \text { (females) and } 60 \mathrm{~g} \text { (males) } \\
\text { - Drinking lasting more than a week -- } \\
\text { Drinking problems (after treatment) }\end{array}$ & Yes & $\mathrm{T} / \mathrm{PT}$ & 12 & $31 \% / 16 \%$ \\
\hline 6 & $\begin{array}{l}\text { Witteman et } \\
\text { al., } 2015\end{array}$ & Risk factors & $\begin{array}{l}\text { 1) Any drinking } \\
\text { 2) Threshold ( } 6 \text { standard drinks) } \\
\text { 3) Problematic drinking (determined by } \\
\text { participants) }\end{array}$ & No & PT & 3 & $\begin{array}{l}47 \% / 66 \% \\
25 \% / 40 \% \\
29 \% / 43 \%\end{array}$ \\
\hline 7 & $\begin{array}{l}\text { Estopiñán et } \\
\text { al., } 2009\end{array}$ & $\begin{array}{l}\text { Type of } \\
\text { treatment }\end{array}$ & $\begin{array}{l}\text { 1) Threshold ( } 6 \text { standard drinks) or } 2 \text { ) } \\
\text { More than } 5 \text { drinking episodes in a week }\end{array}$ & Yes & $\mathrm{T} / \mathrm{PT}$ & 12 & $\begin{array}{l}7 \% / 14 \% \\
* \star * 30 \% / 60 \%\end{array}$ \\
\hline 8 & $\begin{array}{l}\text { Moos et al., } \\
2005\end{array}$ & $\begin{array}{l}\text { Type of } \\
\text { treatment }\end{array}$ & $\begin{array}{l}\text { 1) Threshold ( } 3 \text { ounces) - Alcohol } \\
\text { intoxication - Drinking problems }\end{array}$ & No & PT & 192 & $\begin{array}{l}38 \% \\
* * * 57 \%\end{array}$ \\
\hline 9 & $\begin{array}{l}\text { Bennett et } \\
\text { al., } 2005\end{array}$ & $\begin{array}{l}\text { Relapse } \\
\text { prevention } \\
\text { training }\end{array}$ & $\begin{array}{l}\text { 1) Any drinking } \\
\text { 2) Threshold ( } 9 \text { standard drinks) - } 3 \\
\text { consecutive drinking episodes }\end{array}$ & No & PT & 12 & $\begin{array}{l}69 \% \\
\star * \star 83 \% \\
55 \% \\
* * * 74 \%\end{array}$ \\
\hline 10 & $\begin{array}{l}\text { Demirbas et } \\
\text { al., } 2012\end{array}$ & $\begin{array}{l}\text { Type of } \\
\text { treatment }\end{array}$ & $\begin{array}{l}\text { 1) Any drinking - } 3 \text { consecutive drinking } \\
\text { episodes }\end{array}$ & No & PT & 6 & $57 \%$ \\
\hline 11 & $\begin{array}{l}\text { Mueller et al., } \\
2007\end{array}$ & $\begin{array}{l}\text { Type of } \\
\text { treatment }\end{array}$ & 1) Any drinking & No & PT & 12 & $\begin{array}{l}14 \% / 40 \% / \\
56 \% / 38 \% / \\
\star * \star 29 \% / 43 \% \\
/ 50 \% / 41 \%\end{array}$ \\
\hline 12 & $\begin{array}{l}\text { Feeney et al., } \\
2002\end{array}$ & $\begin{array}{l}\text { Type of } \\
\text { treatment }\end{array}$ & $\begin{array}{l}\text { 1) Any drinking or 2) Withdrew from } \\
\text { treatment without advising }\end{array}$ & No & $\mathrm{T}$ & 3 & $\begin{array}{l}62 \% \\
* * * 86 \%\end{array}$ \\
\hline 13 & $\begin{array}{l}\text { Martínez et } \\
\text { al., } 2014\end{array}$ & $\begin{array}{l}\text { Coping } \\
\text { strategies }\end{array}$ & 1) Threshold (determined by participants) & No & $\mathrm{T} / \mathrm{PT}$ & 6 & $22 \%$ \\
\hline 14 & $\begin{array}{l}\text { Papachristou } \\
\text { et al., } 2014\end{array}$ & Risk factors & 1) Any drinking - 2 drinking episodes & Yes & PT & 3 & $0 \%$ \\
\hline 15 & $\begin{array}{l}\text { Vielva et al., } \\
2001\end{array}$ & Risk factors & 1) Any drinking & No & PT & 6 & $42 \%$ \\
\hline 16 & $\begin{array}{l}\text { Allsop et al., } \\
2000\end{array}$ & Risk factors & $\begin{array}{l}\text { 1) Threshold ( } 31 \text { standard drinks) - } \\
\text { Consumption in } 3 \text { days }\end{array}$ & Yes & PT & 12 & $70 \%$ \\
\hline 17 & Strowig, 2000 & Risk factors & 1) Any drinking & No & PT & 12 & $46 \%$ \\
\hline 18 & $\begin{array}{l}\text { Neto et al., } \\
2008\end{array}$ & $\begin{array}{l}\text { Type of } \\
\text { treatment }\end{array}$ & 1) Any drinking & No & PT & 6 & - \\
\hline
\end{tabular}

Notes:

*T = evaluation of relapse during treatment; $\mathrm{PT}=$ evaluation of relapse after treatment.

** Different outcomes were recorded, but not necessarily because of a lapse/relapse distinction.

*** In those studies that compared two treatments, the relapse rate for the second one is described in the bottom line. 
As Table 1 shows, in some studies definitions based on a dimension were employed as comparable to definitions based on a different dimension. For instance, relapse was defined during treatment as any drinking, and after treatment defined as three drinking episodes of $30 \mathrm{~g}$ of alcohol for females and $60 \mathrm{~g}$ for males (Bottlender \& Soyka, 2004). In another case, researchers defined relapse in such a way as to suggest that different dimensions of relapse were equivalent (e.g. a threshold equivalent to the frequency of consumption or negative consequences) (Estopiñán, Poza, Martín, \& García, 2009; Moos \& Moos, 2006).

In relation to the conceptualization of the relapse as a process, Table 1 also shows the lapse/relapse distinction. Only $27 \%$ of the studies differentiated both treatment outcomes: any drinking and a threshold of consumption were used to identify a lapse; a threshold of drinking, drinking frequency, and negative consequences associated with drinking were used to define a relapse. In some studies, researchers measured more than one outcome (e.g. any drinking and drinking $60 \mathrm{~g}$ of alcohol) not by the lapse/relapse distinction, but because of the recognition of the lack of consensus with respect to the definition of the term.

The lapse/relapse distinction and the record of different outcomes allowed the assessment of the predictive value of different definitions. For instance, Maisto, Pollock, Cornelius, Lynch, and Martin (2003) assess relapse using different definitions: (1) any drinking after four days of abstinence; (2) heavy drinking after four days of abstinence; (3) any drinking with problems after four days of abstinence; and (4) heavy drinking with problems after four days of abstinence. The main results showed that definitions of heavy drinking have a predictive utility independent from any drinking definition. Heavy drinking definitions make better predictions about drinking variables (e.g. number of drinking episodes and drinks per day), while any drinking constitute a significant predictor of the current diagnosis of alcohol dependence.

In the same vein, results showed that relapse rate, defined as a threshold of drinking, was affected by training to detect early warning signs of relapse, but this training did not affect relapse rate when measured as any drinking. Bennett et al. (2005) compared two groups, both enrolled in a standard treatment program, but the experimental group received 15 additional training sessions to detect early warning signs of relapse. Results showed that the additional training reduced the occurrence of heavy drinking (nine standard drinks in three consecutive days), but did not affect measures of any drinking.

Finally, the recording of more than one treatment outcome was useful in specifying the amount of alcohol behind any drinking definition. For instance, using the definition of any drinking, Wetzel et al. (2004) reported a relapse rate of $48 \%$ three months after treatment and 77\% after 12 months. But they also measured relapse using a threshold of $60 \mathrm{~g}$ of alcohol; with this definition the relapse rate was very similar to that observed with any drinking ( $46 \%$ and $76 \%$, respectively). This second measure allows the clarification that, at least for the study of Wetzel et al. (2004), the high relapse rate can be related to the way heavy drinking is classified by any drinking measure.

The inclusion criteria of participants in the different studies were based on a diagnosis following the third and fourth version of the Diagnostic and Statistical Manual of Mental Disorders. As a complement to the diagnosis, only $44 \%$ of the articles describe some characteristics of consumption patterns at the group level before treatment (see Table 2).

Table 2

Studies that reported at group level some alcohol drinking dimensions before treatment

\begin{tabular}{|c|c|c|c|c|}
\hline Study & Drinking Episode (Frequency) & $\begin{array}{l}\text { Amount of alcohol (Mean } \\
\text { or maximum value) }\end{array}$ & Negative consequences & Time drinking \\
\hline Wetzel et al., 2004 & Yes & Yes & - & - \\
\hline Mertens et al., 2012 & - & - & Yes & Yes \\
\hline Bottlender et al., 2004 & - & Yes & - & - \\
\hline Witteman et al., 2015 & Yes & Yes & - & - \\
\hline Moos et al., 2006 & Yes & Yes & Yes & Yes \\
\hline Bennett et al., 2005 & Yes & - & - & Yes \\
\hline Feeney et al., 2002 & - & Yes & - & - \\
\hline Neto et al., 2008 & Yes & Yes & - & Yes \\
\hline
\end{tabular}

With respect to the analyses of individual processes, only one article described individual data. Results from the study of Zywiak et al. (2006) showed that the number of relapses, defined as any drinking after four days of abstinence, were different in particular cases. Thus, in the six evaluations conducted during the time the study took place (12 months), only $13 \%$ of the participants reported six relapses, $18 \%$ present a single relapse, and $22 \%$ relapsed on three occasions. The study does not specify the moments when participants experienced a relapse. 
On the other hand, one objective of the present review was to identify possible theoretical and/or empirical justifications to favor a specific definition of relapse. Relapse was explicitly measured using different thresholds for males and females (e.g. four standard drinks for females and five standard drinks for males, or $30 \mathrm{~g}$ and $60 \mathrm{~g}$, respectively), considering that the effects of alcohol depend on the size and weight of people. A second justification was the definition of relapse as any drinking, to consider early actions during treatment. But researchers defined relapse recognizing the lack of consensus in the definition.

Finally, Table 3 shows the relapse rate as a function of the definition of relapse. A relapse rate comparison (obtained in the same study) is made using any drinking and the threshold of drinking definitions. Results confirm that the way relapse is defined leads to important differences in relapse rates, at least considering these two dimensions.

Table 3

Studies that allow a comparison of relapse rate considering different definitions (any drinkings and a threshold)

\begin{tabular}{|c|c|c|c|c|c|c|c|c|c|}
\hline & Bottlender & Witteman & Wetzel & Maisto & Witteman & Bennett & Maisto & Wetzel & Bennett \\
\hline Threshold & $16 \%$ & $25 \%$ & $46 \%$ & $50 \%$ & $40 \%$ & $55 \%$ & $62 \%$ & $76 \%$ & $74 \%$ \\
\hline Any Drinking & $31 \%$ & $47 \%$ & $49 \%$ & $60 \%$ & $66 \%$ & $69 \%$ & $74 \%$ & $77 \%$ & $86 \%$ \\
\hline
\end{tabular}

\section{Discussion}

A systematic review was conducted to evaluate the asymmetry between the conceptual and operational definition of relapse. In general, the gap between operational definitions and the understanding of relapse as a drinking pattern and process of return to problematic drinking persists. The results obtained exemplify that consumption patterns are usually reduced to the amount of alcohol, any drinking or drinking over a given threshold (an amount of alcohol that ranged from 4 to 31 standard drinks). A smaller proportion of studies measure relapse considering negative consequences and drinking frequency. Also, relapse is measured as a discrete outcome: only $27 \%$ of the studies distinguish between lapse and relapse, even though each measure seems to be associated with different treatment outcomes. Before treatment, some elements of the drinking pattern were measured in only $44 \%$ of the studies; only one study described the analyses of individual processes and multiple episodes.

Results show that any drinking remains the most frequent operationalization of relapse, probably because it is easy to measure and results suggest it allows for the study of relapse to some extent. However, some problems can be enumerated for the definition of any drinking: (1) it does not allow the operationalization of the relapse and recovery from addiction as a process, (2) it is not a sensitive measure of the problematic drinking pattern, (3) it is only a partial predictor of posttreatment drinking patterns, and (4) it is uninformative.

With respect to the first problem, our findings suggest there is an asymmetry in the conceptualization of relapse as a dynamic and complex process and its operationalization as a discrete result. The study of relapse as a process supposes that lapses do not imply resistance to change. From a theoretical position, it can be argued that behavioral change takes place across different stages: any drinking after treatment can differ from any drinking before treatment, where people do not even contemplate the need to reduce or abstain from drinking (DiClemente \& Prochaska, 1998). On the other hand, empirical data suggest that clinical change in addictive behavior and other conditions (e.g. depression) is discontinued and nonlinear (Hayes, Laurenceau, Feldman, Strauss, \& Cardaciotto, 2007). In this sense, the study of relapse as a discrete outcome does not describe the typical course in post-treatment drinking trajectories that show a prolongation of abstinence, a shortening in the duration of drinking episodes, the reducing of episodes' frequency or the reduction in number of drinks per day (Engel et al., 2016; Miller, 1996; Scott et al., 2005; Sobell et al., 2003).

Another argument that can support a processes conceptualization is the abstinence violation effect. According to some authors (Kirchner, Shiffman, \& Wileyto, 2012; Marlatt \& George, 1984), identifying eventual alcohol drinking as a part of the process of change can reduce the probability that any drinking may result in a return to problematic drinking. As Ramo et al. (2012) state, relapse, defined in a dynamic way, represents a reference point from which patients under treatment may reevaluate their own treatment course.

Conversely, conceptualizing relapse as a process instead of a discrete outcome can promote the systematic analyses of multiple drinking episodes. In our review, the analysis of multiple episodes was not a central interest. Decisions about treatment course and the assessment of treatment effectiveness can be more realistic if they are based on a set of events rather than a single one. Typically, researchers evaluated a small number of drinking episodes (if more than one drinking 
episodes were measured), but also treated episodes as independent units (Maisto \& Connors, 2006), making it difficult to characterize the problem across time (e.g. how the dimensions of relapse change, and the timing and size of these changes, etc.), as the results suggest. Because alcohol drinking is commonly conceptualized as a chronic condition (Donovan \& Marlatt, 2005; Koob \& Volkow, 2009; McLellan, Lewis, O’Brien, \& Kleber, 2000; Moore et al., 2014; Scott et al., 2005; Stockwell, 1999), the analyses of multiple episodes can create the opportunity to improve prevention strategies or specify action mechanisms targeting risk factors.

The second problem with the definition of any drinking is related to the limits that it imposes on the potential of getting a closer picture about the return to a problematic drinking (at individual and group level). The results of Wetzel et al. (2004) shows that the registration of different outcomes allows a better understanding of relapse processes. According to Baer (2002), one indicator used to identify problematic drinking is the amount of alcohol consumed per episode. Results in the review offer some support to this claim, suggesting that any drinking can be viewed as part of so-called controlled drinking (Zweben \& Cisler, 2003), and that the amount of alcohol (threshold) is a relevant dimension of relapse (Baer, 2002; Cisler \& Zweben, 1999; Maisto et al., 2003; Sobell et al., 2003; Witkiewitz \& Masyn, 2008). The definition of any drinking does not allow the assessment of whether a specific drinking episode is similar or can be characterized as heavy drinking, and to clarify if this category can be generalized to individuals.

In the same vein, negative consequences are another important indicator excluded by the definition of any drinking. Both the amount of alcohol and negative consequences are indicators used to delineate problematic drinking, but their relationship remains unknown (Baer, 2002; Ham \& Hope, 2003); the interactions of these dimensions can only be explored if the definition of any drinking is abandoned. Even with the challenge of determining what constitute negative consequences and their weight at the individual level, problems related to alcohol consumption are an important reference point to assess clinical progress. Nevertheless, a smaller proportion of studies use this dimension to operationalize relapse.

The third problem of the definition of any drinking is related to the predictive utility of this treatment outcome. As was already reported in other documents, any drinking does not necessarily imply a progress in relapse considering more complex treatment outcomes (Stout, 2000; Winters, Stinchfield, Opland, Weller, \& Latimer, 2000), even with more addictive substances such as heroin (Gossop, Stewart, Browne, \& Marsden, 2002). In the same vein, results obtained with the definition of any drinking are not associated with changes in post-treatment drinking patterns (Bennett et al., 2005; Maisto et al., 2003).

Finally, considering a pragmatic criterion, the definition of any drinking is problematic because it represents an undescriptive treatment outcome and consequently, only partially reports on the process (or processes) of recovery from addiction. Since definitions of the relapse are associated with different results (Maisto et al., 2003), the strategies and actions of health professional can more effectively improve treatment if they consider a better description of the entire drinking pattern (Wetzel et al., 2004).

Based on these four aspects, an alternative is to measure treatment outcomes using a composed index that reflect the whole consumption pattern before treatment and how it changes across drinking episodes during and after treatment at the individual and group level. With this aim in mind, the first challenge is to record and describe the consumption pattern, enabling within-subject and between-subject comparisons. To achieve this goal, we propose to normalize the value of each dimension of the drinking pattern, that is, divide the value of a dimension by some parameter. For example, in the case of amount of alcohol, we can divide the average of alcohol consumed per drinking episode by the heavy drinking parameter: if average consumption per drinking episode is higher than heavy drinking, the amount index will result in a value $>1$; if consumption is lower than heavy drinking the amount index will give a result $<1$; if individual consumption is equal to heavy drinking, the amount index will be exactly 1 .

Normalized values can be applied to the rest of the dimensions, taking as a reference the value of each dimension before treatment at the individual level given the ignorance of a parameter equivalent to heavy drinking. So, in the case of drinking frequency, if a subject reported an average of five drinking episodes per month before treatment, and this frequency constituted a characteristic of his/her problematic drinking, drinking with a frequency higher than five episodes in a month will result in a frequency index $>1$; if their drinking frequency is lower than five drinking episodes then the frequency index will give a result $<1$; if the frequency doesn't not change across time, the frequency index will be 1 . A similar logic can be applied to negative consequences and duration of drinking episodes, or other parameters.

We believe that a normalized composed index can facilitate: (1) cross-study comparisons avoiding the use of several definitions that are based on partial descriptions of the drinking pattern; (2) clarifying the relation (e.g. additive or multiplicative) between dimensions, providing a more precise description of these change (or not) over time, and assessing its specific predictive and informative value in the 
recovery from alcoholism; and (3) tracking individual differences in their recovery from addiction.

Thus, the registration of the composed index can be conducted taking the drinking episode as the basic unit of analysis. Following Stout (2000), researchers can set the beginning of an episode as any drinking and define its end as 24 hours of abstinence. As Miller (1996) suggests, for each episode researchers can quantify the amount of alcohol (not limited to any drinking, heavy drinking or similar categories), the frequency of drinking episodes in a month, the average duration of the episodes (amount of alcohol consumed in a specific temporal window), and the number and types of negative consequences associated with alcohol drinking (ideally determined for individual cases). Other aspects can be described to make the pattern of alcohol drinking even more precise: type of beverages, the context of drinking, the temporal distribution of drinking episodes, etc. The composed index must reflect the consumption pattern of alcohol before treatment and contrast it to changes during and after treatment; the reduction of negative consequences, consumption frequency, and the amount and/or duration of the drinking episodes may represent different levels of progress at the individual level.

A final suggestion for the study of relapse is to use relapse definitions that are sensitive to substance type. Research on relapse based on a general diagnosis such as substance use is common (e.g. Anderson, Ramo, Schulte, Cummins, \& Brown, 2008; Brown, Saraganian, Tremblay, \& Annis, 2002; Moore et al., 2014; Tate, Brown, Glasner, Unrod, \& McQuaid, 2006), and may limit the comprehension of relapse processes by assuming that a singular definition is appropriate to describe relapse processes under different conditions. For example, a general inspection suggests that the lapse/relapse distinction is more common in the analyses of smoking problems than in alcohol; in fact, only the lapse comes into the analysis when smoking is the treated problem (Muraven, 2010; Sheffer et al., 2014). On the contrary, in the literature on alcohol, as results showed, a small proportion of the studies distinguish between lapse and relapse. Consequently, any use is usually a lapse in smoking studies while any drinking represents a relapse for research on alcoholism.

In the same vein, relapse in smoking behavior is usually studied using an ecological momentary assessment instead of prospective and retrospective designs. This evaluation in the heat of the moment, as described by Van Zundert, Kuntsche, and Engels (2012), may be complex to conduct in studies with substances such as amphetamine, cocaine, heroin, or even alcohol due the effects of the substance, in addition to the contexts and patterns of use associated with each substance.
Addictive behavior usually involves the use of more than one substance and the study of relapse needs to be sensitive to the interaction of different substances. For example, Van Zundert et al. (2012) found that alcohol drinking was strongly associated to smoking lapses (any use), but not with a relapse. On the other hand, comparisons between smokers and nonsmokers suggest that smoking appears to facilitate abstinence from alcohol drinking (Schmidt \& Smolka, 2001; Toneatto, Sobell, Sobell, \& Kozlowski, 1995). Informative research related to the definition(s), risk factors and strategies to prevent relapse can result from the systematic analyses of similarities, differences, and relations between the types of substance use (Holt, Litt, \& Cooney, 2012). Considering differences in the way relapse is measured can improve the treatment of poly-users.

\section{Conclusion}

The large diversity of definitions in the study of relapse remains a common problem because these definitions do not reflect drinking patterns nor capture the notion of relapse as a process, limiting the study of individual processes and making cross-study comparisons difficult. Even with the limitation of the no agreement on an operational definition of relapse, the literature shows growing data that allow the delineation of risk factors and effective prevention strategies. Nevertheless, in order to improve our understanding of relapse, analysis needs to move away from discrete treatment outcomes to consider patterns of alcohol drinking and measure their changes across drinking episodes. Generating systematic descriptions of each dimension of drinking patterns and tracing consumption trajectories over time using a composed index that reflects individual and group differences before, during and after treatment may prove useful.

\section{Limitations of the study}

Finally, the present review has some limitations. First, the inclusion criteria were very specific, resulting in an easily compared sample of studies, but also in a small number of recently-published documents (i.e. in the last five years). Based on the present results, future reviews can also include studies with only pharmacological interventions and/or different substances (e.g. illegal drugs) to increase the sample. Second, in the same vein, the small number of studies does not allow the assessment of specific questions. One example would be if the association of some risk factors to relapse depends on the definition of relapse. Third, likely due to the inclusion criteria, none of the articles reviewed defined relapse using categories related to drinking trajectories or other broader concepts. 


\section{References}

Allsop, S., Saunders, B., \& Phillips, M. (2000). The process of relapse in severely dependent male problem drinkers. Addiction, 95(1), 95-106. doi: 10.1046/j.1360-0443.2000.9519510.x

Anderson, K. G., Ramo, D. E., Schulte, M. T., Cummins, K., \& Brown, S. A. (2008). The impact of relapse predictors on psychosocial functioning of SUD youth one year after treatment. Substance Abuse, 29(2), 97-106. doi: 10.1080/08897070802093411

Baer, J. S. (2002). Student factors: Understanding individual variation in college drinking. Journal of Studies on Alcohol, Supplement(s14), 40-53. doi: 10.15288/jsas.2002.s14.40

Bennett, G. A., Withers, J., Thomas, P. W., Higgins, D. S., Bailey, J., Parry, L., \& Davies, E. (2005). A randomised trial of early warning signs relapse prevention training in the treatment of alcohol dependence. Addictive Behaviors, 30(6), 11111124. doi: 10.1016/j.addbeh.2004.10.008

Bottlender, M., \& Soyka, M. (2004). Impact of craving on alcohol relapse during, and 12 months following, outpatient treatment. Alcohol and Alcoholism, 39(4), 357-361. doi: 10.1093/alcalc/agh073

Brown, T. G., Seraganian, P., Tremblay, J., \& Annis, H. (2002). Process and outcome changes with relapse prevention versus 12-Step aftercare programs for substance abusers. Addiction, 97(6), 677-689. doi: 10.1046/j.1360-0443.2002.00101.x

Card, N. A. (2012). Applied meta-analysis for social science research. New York: Guilford Publications. doi: 10.1111/insr.12011_17

Chung, T., \& Maisto, S. (2006). Relapse to alcohol and other drug use in treated adolescents: Review and reconsideration of relapse as a change point in clinical course. Clinical Psychology Review, 26(2), 149-161. doi: 10.1016/j.cpr.2005.11.004

Chung, T., Maisto, S. A., Cornelius, J. R., \& Martin, C. S. (2004). Adolescents' alcohol and drug use trajectories in the year following treatment. Journal of Studies on Alcohol, 65(1), 105-114. doi: 10.15288/jsa.2004.65.105

Cisler, R. A., \& Zweben, A. (1999). Development of a composite measure for assessing alcohol treatment outcome: Operationalization and validation. Alcoholism: Clinical and Experimental Research, 23(2), 263-271. doi: 10.1111/j.15300277.1999.tb04109.x

Demirbas, H., Ilhan, I. O., \& Dogan, Y. B. (2012). Ways of problem solving as predictors of relapse in alcohol dependent male inpatients. Addictive Behaviors, 37(1), 131-134. doi: 10.1016/j. addbeh.2011.08.007
DiClemente, C. C., \& Prochaska, J. O. (1998). Toward a comprehensive, transtheoretical model of change: Stages of change and addictive behaviors. In W. R. Miller \& N. Heather (Eds.), Applied clinical psychology. Treating addictive behaviors (pp. 3-24). doi: 10.1007/978-1-4899-1934-2_1

Donovan, D. M., \& Marlatt, G. A. (2005). Assessment of addictive behaviors (2nd Ed.). New York: Guilford Press.

Engel, K., Schaefer, M., Stickel, A., Binder, H., Heinz, A., \& Richter, C. (2016). The role of psychological distress in relapse prevention of alcohol addiction. Can high scores on the SCL-90-R predict alcohol relapse?. Alcohol and Alcoholism, 51(1), 27-31. doi: 10.1093/alcalc/agv062

Estopiñán, P. C., Poza, A. P., Martín, P. S., \& García, C. P. (2009). Terapia grupal en prevención de recaídas del alcoholismo frente a seguimiento ambulatorio habitual. Adicciones, 21(1), 15-20. doi: 10.20882/adicciones.247

Feeney, G. F., Young, R. M. D., Connor, J. P., Tucker, J., \& McPherson, A. (2002). Cognitive behavioural therapy combined with the relapse-prevention medication acamprosate: are short-term treatment outcomes for alcohol dependence improved? Australian and New Zealand Journal of Psychiatry, 36(5), 622-628. doi: 10.1046/j.1440-1614.2002.01019.x

Gossop, M., Stewart, D., Browne, N., \& Marsden, J. (2002). Factors associated with abstinence, lapse or relapse to heroin use after residential treatment: protective effect of coping responses. Addiction, 97(10), 1259-1267. doi: 10.1046/j.1360-0443.2002.00227.x

Greenwood, G. L., Woods, W. J., Guydish, J., \& Bein, E. (2001). Relapse outcomes in a randomized trial of residential and day drug abuse treatment. Journal of Substance Abuse Treatment, 20(1), 1523. doi: 10.1016/S0740-5472(00)00147-1

Ham, L. S., \& Hope, D. A. (2003). College students and problematic drinking: A review of the literature. Clinical Psychology Review, 23(5), 719-759. doi: 10.1016/S0272-7358(03)00071-0

Hayes, A. M., Laurenceau, J. P., Feldman, G., Strauss, J. L., \& Cardaciotto, L. (2007). Change is not always linear: The study of nonlinear and discontinuous patterns of change in psychotherapy. Clinical Psychology Review, 27(6), 715-723. doi: 10.1016/j.cpr.2007.01.008

Holt, L. J., Litt, M. D., \& Cooney, N. L. (2012). Prospective analysis of early lapse to drinking and smoking among individuals in concurrent alcohol and tobacco treatment. Psychology of Addictive Behaviors, 26(3), 561-572. doi: 10.1037/a0026039 
Kirchner, T. R., Shiffman, S., \& Wileyto, E. P. (2012). Relapse dynamics during smoking cessation: recurrent abstinence violation effects and lapse-relapse progression. Journal of Abnormal Psychology, 121(1), 187-197. doi: http://doi. org/10.1037/a0024451

Koob, G. F., \& Volkow, N. D. (2009). Neurocircuitry of addiction. Neuropsychopharmacology, 35, 217238. doi: $10.1038 / n p p .2009 .110$

Maisto, S. A., Pollock, N. K., Cornelius, J. R., Lynch, K. G., \& Martin, C. S. (2003). Alcohol relapse as a function of relapse definition in a clinical sample of adolescents. Addictive Behaviors, 28(3), 449459. doi: 10.1016/S0306-4603(01)00267-2

Maisto, S. A., \& Connors, G. J. (2006). Relapse in the addictive behaviors: Integration and future directions. Clinical Psychology Review, 26(2), 229-231. doi: 10.1016/j.cpr.2005.11.009

Maisto, S. A., Witkiewitz, K., Moskal, D., \& Wilson, A. D. (2016). Is the Construct of Relapse Heuristic, and Does It Advance Alcohol Use Disorder Clinical Practice? Journal of Studies on Alcohol and Drugs, 77(6), 849-858. doi: 10.15288/ jsad.2016.77.849

Marlatt, G. A., \& Donovan, D. M. (Eds.). (2005). Relapse prevention: Maintenance strategies in the treatment of addictive behaviors. Guilford Press.

Marlatt, G. A., \& George, W. H. (1984). Relapse prevention: Introduction and overview of the model. British Journal of Addiction, 79(3), 261273. doi: 10.1111/j.1360-0443.1984.tb00274.x

Marlatt, G. A., \& Witkiewitz, K. (2002). Harm reduction approaches to alcohol use: Health promotion, prevention, and treatment. Addictive Behaviors, 27(6), 867-886. doi: 10.1016/ S0306-4603(02)00294-0

Martínez, K. I., Pedroza, F. J., Salazar, M.L., \& Vacio, M. (2014). Estrategias de enfrentamiento y número de recaídas en el proceso de cambio de adolescentes que abusan del alcohol. Revista Mexicana de Análisis de la Conducta, 40(3), 11-31.

McKay, J. R., Franklin, T. R., Patapis, N., \& Lynch, K. G. (2006). Conceptual, methodological, and analytical issues in the study of relapse. Clinical Psychology Review, 26(2), 109-127. doi: 10.1016/j.cpr.2005.11.002

McLellan, A. T., Lewis, D. C., O’Brien, C. P., \& Kleber, H. D. (2000). Drug dependence, a chronic medical illness: Implications for treatment, insurance, and outcomes evaluation. Journal of the American Medical Association, 284(13), 1689-1695. doi: 10.1001/jama.284.13.1689
Mertens, J. R., Kline-Simon, A. H., Delucchi, K. L., Moore, C., \& Weisner, C. M. (2012). Ten-year stability of remission in private alcohol and drug outpatient treatment: Non-problem users versus abstainers. Drug \& Alcohol Dependence, 125(1), 67-74. doi: 10.1016/j.drugalcdep.2012.03.020

Miller, W. R. (1996). What is a relapse? Fifty ways to leave the wagon. Addiction, 91(12s1), 15-28. doi: 10.1046/j.1360-0443.91.12s1.6.x

Moher, D., Shamseer, L., Clarke, M., Ghersi, D., Liberati, A., Petticrew, M., ... \& Stewart, L. A. (2015). Preferred reporting items for systematic review and meta-analysis protocols (PRISMA-P) 2015 statement. Systematic reviews, 4(1), 1. doi: 10.1186/2046-4053-4-1

Moore, T. M., Seavey, A., Ritter, K., Mcnulty, J. K., Gordon, K. C., \& Stuart, G. L. (2014). Ecological momentary assessment of the effects of craving and affect on risk for relapse during substance abuse treatment. Psychology of Addictive Behaviors, 28(2), 619624. doi: 10.1037/a0034127

Moos, R. H., \& Moos, B. S. (2006). Rates and predictors of relapse after natural and treated remission from alcohol use disorders. Addiction, 101(2), 212222. doi: 10.1111/j.1360-0443.2006.01310.x

Moyer, A., Finney, J. W., \& Swearingen, C. E. (2002). Methodological characteristics and quality of alcohol treatment outcome studies, 1970-98: An expanded evaluation. Addiction, 97(3), 253-263. doi: 10.1046/j.1360-0443.2002.00017.x

Mueller, S. E., Petitjean, S., Boening, J., \& Wiesbeck, G. A. (2007). The impact of self-help group attendance on relapse rates after alcohol detoxification in a controlled study. Alcohol and Alcoholism, 42(2), 108-112. doi: 10.1093/alcalc/agl122

Mundt, J. C., Moore, H. K., \& Bean, P. (2006). An interactive voice response program to reduce drinking relapse: A feasibility study. Journal of Substance Abuse Treatment, 30(1), 21-29. doi: 10.1016/j.jsat.2005.08.010

Muraven, M. (2010). Practicing self-control lowers the risk of smoking lapse. Psychology of Addictive Behaviors, 24(3), 446-452. doi: 10.1037/ a0018545

Neto, D., Lambaz, R., Aguiar, P., \& Chick, J. (2008). Effectiveness of sequential combined treatment in comparison with treatment as usual in preventing relapse in alcohol dependence. Alcohol and Alcoholism, 43(6), 661-668. doi: 10.1093/alcalc/agn075

Papachristou, H., Nederkoorn, C., Giesen, J. C., \& Jansen, A. (2014). Cue reactivity during treatment, and not impulsivity, predicts an initial lapse after treatment in alcohol use disorders. Addictive Behaviors, 39(3), 737-739. doi: 10.1016/j.addbeh.2013.11.027 
Potgieter, A. S., Deckers, F., \& Geerlings, P. (1999). Craving and relapse measurement in alcoholism. Alcohol and Alcoholism, 34(2), 254-260. doi: 10.1093/alcalc/34.2.254

Rahill, G. J., Pinto Lopez, E., Vanderbiest, A., \& Rice, C. (2009). What is relapse? A contemporary exploration of treatment of alcoholism. Journal of Social Work Practice in the Addictions, 9(3), 245-262. doi: 10.1080/15332560902841816

Ramo, D. E., Prince, M. A., Roesch, S. C., \& Brown, S. A. (2012). Variation in substance use relapse episodes among adolescents: A longitudinal investigation. Journal of Substance Abuse Ttreatment, 43(1), 44-52. doi: 10.1016/j. jsat.2011.10.003

Schmidt, L. G., \& Smolka, M. (2001). Relapse prevention in alcoholics by cigarette smoking? Involvement of nicotinic-dopaminergic mechanisms. Alcohol, 24(2), 111-115. doi: 10.1016/S0741-8329(01)00129-X

Scott, C. K., Dennis, M. L., \& Foss, M. A. (2005). Utilizing recovery management checkups to shorten the cycle of relapse, treatment reentry, and recovery. Drug and Alcohol Dependence, 78(3), 325-338. doi: 10.1016/j.drugalcdep.2004.12.005

Sheffer, C. E., Christensen, D. R., Landes, R., Carter, L. P., Jackson, L., \& Bickel, W. K. (2014). Delay discounting rates: A strong prognostic indicator of smoking relapse. Addictive Behaviors, 39(11), 1682-1689 doi: 10.1016/j.addbeh.2014.04.019

Sobell, L. C., Sobell, M. B., Connors, G. J., \& Agrawal, S. (2003). Assessing drinking outcomes in alcohol treatment efficacy studies: selecting a yardstick of success. Alcoholism: Clinical and Experimental Research, 27(10), 1661-1666. doi: 10.1097/01. ALC.0000091227.26627.75

Stockwell, T. (1999). Should a few hours of therapy change behavior 3 years later? Addiction, 94(1), 50-52.

Stout, R. L. (2000). What is a drinking episode? Journal of Studies on Alcohol, 61(3), 455-461. doi: $10.15288 /$ jsa.2000.61.455

Strowig, A. B. (2000). Relapse determinants reported by men treated for alcohol addiction: the prominence of depressed mood. Journal of Substance Abuse Treatment, 19(4), 469-474.

Takeda, Y., Roper, L., Duff, S., \& Booth, P. G. (2013). Decision-making throughout the whole process of relapse: A qualitative analysis of problem drinkers' accounts of recent episodes. Journal of Substance Use, 18(5), 417-428. doi: 10.3109/14659891.2012.721446
Tate, S. R., Brown, S. A., Glasner, S. V., Unrod, M., \& McQuaid, J. R. (2006). Chronic life stress, acute stress events, and substance availability in relapse. Addiction Research \& Theory, 14(3), 303-322. doi: 10.1080/16066350500262817

Toneatto, A., Sobell, L. C., Sobell, M. B., \& Kozlowski, L. T. (1995). Effect of cigarette smoking on alcohol treatment outcome. Journal of Substance Abuse, 7, 245-252. doi: 10.1016/0899-3289(95)90008-X

Tuithof, M., ten Have, M., van den Brink, W., Vollebergh, W., \& de Graaf, R. (2014). The Relationship between excessive alcohol consumption and alcohol use disorders according to DSM-IV and DSM-5. Alcoholism: Clinical and Experimental Research, 38(1), 249-256. doi: 10.1111/acer.12248

Van Zundert, R. M., Kuntsche, E., \& Engels, R. C. (2012). In the heat of the moment: Alcohol consumption and smoking lapse and relapse among adolescents who have quit smoking. Drug and Alcohol Dependence, 126(1), 200-205. doi: 10.1016/j.drugalcdep.2012.05.016

Vielva, I., \& Iraurgi, I. (2001). Cognitive and behavioural factors as predictors of abstinence following treatment for alcohol dependence. Addiction, 96(2), 297-303. doi: 10.1046/j.1360-0443.2001.96229713.x

Walton, M. A., Castro, F. G., \& Barrington, E. H. (1994). The role of attributions in abstinence, lapse, and relapse following substance abuse treatment. Addictive Behaviors, 19(3), 319-331. doi: 10.1016/0306-4603(94)90033-7

Wetzel, H., Szegedi, A., Scheurich, A., Lorch, B., Singer, P., Schlafke, D., ... \& Hautzinger, M. (2004). Combination treatment with nefazodone and cognitive-behavioral therapy for relapse prevention in alcohol-dependent men: a randomized controlled study. Journal of Clinical Psychiatry, 65(10), 1406-1413. doi: 10.4088/ JCP.v65n1017

Winters, K. C., Stinchfield, R. D., Opland, E., Weller, C., \& Latimer, W. W. (2000). The effectiveness of the Minnesota Model approach in the treatment of adolescent drug abusers. Addiction, 95(4), 601612.doi:10.1046/j.1360-0443.2000.95460111.x

Witkiewitz, K. A., \& Marlatt, G. A. (Eds.). (2011). Therapist's guide to evidence-based relapse prevention. USA: Academic Press.

Witkiewitz, K., \& Masyn, K. E. (2008). Drinking trajectories following an initial lapse. Psychology of Addictive Behaviors, 22(2), 157-167. doi: 10.1037/0893-164X.22.2.157 
Witteman, J., Post, H., Tarvainen, M., de Bruijn, A., Perna, E. D. S., Ramaekers, J. G., \& Wiers, R. W. (2015). Cue reactivity and its relation to craving and relapse in alcohol dependence: a combined laboratory and field study. Psychopharmacology, 232(20), 3685-3696. doi: 10.1007/ s00213-015-4027-6

Zweben, A., \& Cisler, R. A. (2003). Clinical and methodological utility of a composite outcome measure for alcohol treatment research. Alcoholism: Clinical and Experimental Research, 27(10), 1680-1685. doi: 10.1097/01. ALC.0000091237.34225.D7

Zywiak, W. H., Stout, R. L., Trefry, W. B., Glasser, I., Connors, G. J., Maisto, S. A., \& Westerberg, V. S. (2006). Alcohol relapse repetition, gender, and predictive validity. Journal of Substance Abuse Treatment, 30(4), 349-353. doi: 10.1016/j. jsat.2006.03.004 